\title{
Estudo acerca da mortandade de peixes no AHE Ferreira Gomes, rio Araguari, Ferreira Gomes, AP
}

\section{Study about the fish mortality in the AHE Ferreira Gomes, Araguari River, Ferreira Gomes, AP}

\author{
Cecile de Souza Gama ${ }^{1}$ \\ ${ }^{1}$ Instituto de Pesquisas Científicas e Tecnológicas do Amapá, Núcleo de Biodiversidade, Rod, JK, Kn 10 s/n. Fazendinha, Macapá - AP, Brasil. \\ https://orcid.org/0000-0002-5128-6120 E-mail: cecilegama@hotmail.com. *Corresponding author
}

\begin{abstract}
Palavras chave
O rio Araguari hospeda atualmente 3 empreendimentos hidrelétricos em seu curso principal e o empreendimento localizado mais a jusante causou, durante seus testes de operação, a mortalidade de muito

Impacto

Hidrelétrica

Peixes

Araguari

Key-words

Impact

Hydroelectric

Fish

Araguari

espécimes de peixes de forma contínua e repetida. Para descobrir a causa da morte desses peixes foi realizado um estudo pontual em outubro de 2014 onde foram analisados vários exemplares de peixes mortos e analisadas uma série de dados ambientais. Todas as possíveis causas da referida mortalidade foram descartadas devido aos dados recolhidos, exceto a supersaturação de oxigênio na água causada pela ação conjunta do funcionamento das turbinas e do represamento desta água pela ação da maré.

The Araguari River currently hosts 3 hydroelectric projects in its main course and the enterprise located further downstream caused, during the operation tests, the mortality of many fish specimens in a continuous and repeated manner. To find out the cause of the death of these fishes, a one-off study was carried out in October 2014, where several dead fish were analyzed and a series of environmental data were analyzed. All possible causes of such mortality were discarded due to the data collected, except for the supersaturation of oxygen in the water caused by the joint action of turbines and the damming of this water by the action of the tide.
\end{abstract}

\section{INTRODUÇÃO}

Os impactos decorrentes dos represamentos de um rio sobre as assembleias de peixes foram documentados por diversos autores (LOWE-MCCONNELL, 1984; RODRIGUEZ RUIZ, 1998; KUBECKA, 1993; AGOSTINHO et al., 1997; AGOSTINHO et al., 1999) e são as hidrelétricas as principais causadoras da diminuição das populações ou mesmo extinção de espécies de peixes, como relata Araujo e Nunan (2005) para o rio Paraíba do Sul, por exemplo.

Os impactos sobre as populações de peixes acontecem principalmente durante a construção e o enchimento de reservatórios, pois constituem processos intensos e dramáticos, que resultam na criação de um novo ecossistema (BAXTER, 1977), com uma estrutura particular através de uma reorganização do sistema, afetando diretamente as populações de peixes (STRASKRABA; TUNDISI, 2000).

Depois de repetidos eventos de mortandade de peixes na área a jusante do AHE Ferreira Gomes, os quais se iniciaram nos dias 30 e 31 de julho de 2014, foi realizada uma visita ao local entre os dias 6 e 9 de outubro de 2014 a fim de investigar possíveis causas da referida mortandade.

\section{METODOLOGIA}

O AHE Ferreira Gomes localiza-se no rio Araguari, no município de Ferreira Gomes, Estado do Amapá, com eixo de barramento projetado nas coordenadas geográficas $51^{\circ} 11^{\prime} 41,071^{\prime \prime} \mathrm{W} / 00^{\circ} 51^{\prime} 20,126^{\prime \prime} \mathrm{N}$.

Para a investigação da mortandade de peixes a jusante do AHE Ferreira Gomes foram tomadas medidas de qualidade de água sob os parâmetros pH, oxigênio dissolvido (OD), temperatura, turbidez e saturação de oxigênio $\left(\% \mathrm{O}_{2}\right)$ com uma sonda multiparâmetros marca YSI. As medidas foram tomadas em 6 pontos no reservatório (Tabela 1, Figura 1), e em 5 pontos na área à direita do vertedouro, onde o fundo é rochoso com profundidade máxima de 2,8 metros durante a maré vazante (Figura 2). Também foram analisados macroscopicamente alguns peixes encontrados mortos nas margens do rio Araguari, a jusante da represa do AHE Ferreira Gomes.

Para identificar a causa mortis dos peixes, também foram observados alguns exemplares de diferentes espécies encontrados mortos no local. A análise foi realizada apenas macroscopicamente em busca de evidências que indicassem 
o problema.

Tabela 1. Localização geográfica dos pontos de amostragem de água no reservatório do AHE Ferreira Gomes.

\begin{tabular}{|c|c|c|c|}
\hline Ponto & Latitude & Longitude & Descrição \\
\hline 1 & $00^{\circ} 50^{\prime} 57.7^{\prime \prime}$ & $051^{\circ} 11^{\prime} 56.1^{\prime \prime}$ & $\begin{array}{c}\text { Margem } \\
\text { direita do rio } \\
\text { Araguari, } \\
\text { próximo à } \\
\text { margem que } \\
\text { foi alagada }\end{array}$ \\
\hline 2 & $00^{\circ} 51^{\prime} 07.02^{\prime \prime}$ & $051^{\circ} 11^{\prime} 49.4^{\prime \prime}$ & $\begin{array}{l}\text { Próximo à } \\
\text { barragem }\end{array}$ \\
\hline 3 & $00^{\circ} 51^{\prime} 12.2^{\prime \prime}$ & $051^{\circ} 11^{\prime} 50.3^{\prime \prime}$ & $\begin{array}{l}\text { Próximo à } \\
\text { barragem }\end{array}$ \\
\hline 4 & $00^{\circ} 51^{\prime} 22^{\prime \prime}$ & $051^{\circ} 11^{\prime} 51.6^{\prime \prime}$ & $\begin{array}{l}\text { A direita do } \\
\text { vertedouro }\end{array}$ \\
\hline 5 & $00^{\circ} 51^{\prime} 22.8^{\prime \prime}$ & $051^{\circ} 11^{\prime} 52.8^{\prime \prime}$ & $\begin{array}{c}\text { Em frente ao } \\
\text { vertedouro }\end{array}$ \\
\hline 6 & $00^{\circ} 51^{\prime} 29.8^{\prime \prime}$ & $051^{\circ} 1151.6^{\prime \prime}$ & $\begin{array}{l}\text { Em frente à } \\
\text { casa de força }\end{array}$ \\
\hline
\end{tabular}

Figura 1. Localização dos pontos de análise de água a montante da barragem do AHE Ferreira Gomes

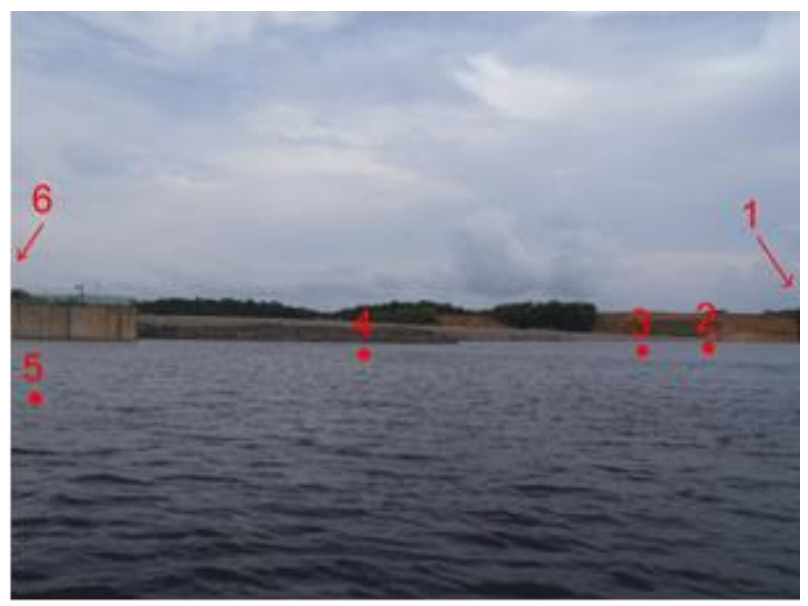

Figura 2. Localização dos pontos de análise de água a jusante da barragem do AHE Ferreira Gomes.

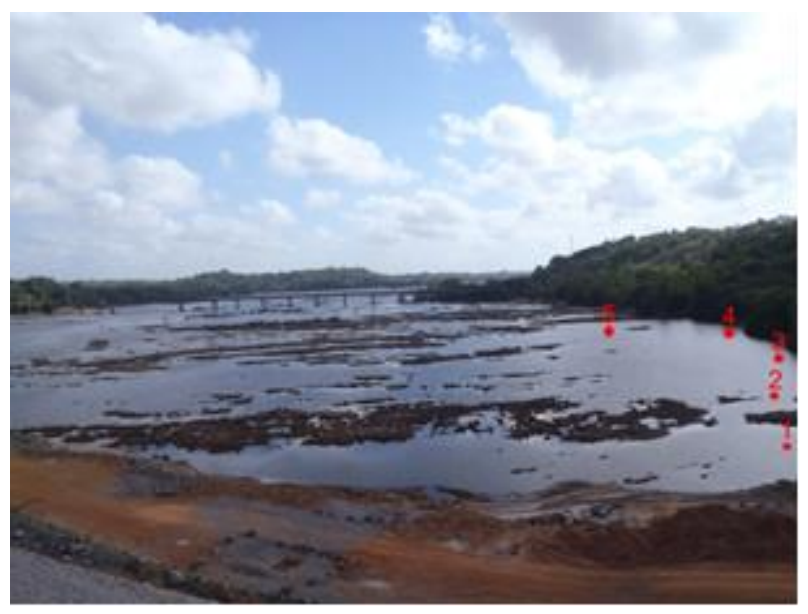

\section{RESULTADOS E DISCUSSÃO}

Várias possíveis causas de mortes de peixes em ambiente natural foram investigadas, algumas puderam ser facilmente descartadas pelas análises realizadas, como listadas a seguir.

- Baixa oxigenação da água

A ocorrência da estratificação térmica da coluna d'água de reservatórios aliada a processos de decomposição no hipolímio podem levar à depleção total do oxigênio nas camadas mais profundas e a decorrente eliminação da comunidade de peixes nelas presentes (AGOSTINHO et al., 1992).

A temperatura da água interfere diretamente na solubilidade do $\mathrm{O}_{2}$ na água, quanto maior a temperatura, menor a solubilidade de gases. Desta forma, águas de rios ou lagos aquecidas natural ou artificialmente devido a poluição térmica contém menos oxigênio dissolvido.

Caso a água do fundo do reservatório, hipolímio, apresentasse níveis intoleráveis de oxigênio, essa água poderia estar afetando os peixes à jusante no momento da sua passagem pelo vertedouro ou pela casa de força, caso essa movimentação não causasse aeração suficiente.

No entanto, foram tomadas medidas de Temperatura e Oxigênio dissolvido em 6 pontos a montante da represa, na área do reservatório (Tabela 1) e não foi encontrada estratificação de temperatura ao longo da coluna d'água e mesmo nos pontos mais profundos encontrados (17 e 19 metros) os valores de OD estavam em níveis aceitáveis para a manutenção da vida aquática. $O$ valor mínimo de oxigênio dissolvido (OD) para a preservação da vida aquática, estabelecido pela Resolução CONAMA 357/05(2) é de 5,0 $\mathrm{mg} / \mathrm{L}$, mas existe uma variação na tolerância de espécie para espécie.

Dessa forma elimina-se a hipótese de que a água com baixa oxigenação oriunda do fundo do reservatório estivesse matando os peixes à jusante.

- Eutrofização

A entrada de poluentes orgânicos e inorgânicos, como nitrogênio e fósforo, oriundos de atividades antrópicas desenvolvidas na bacia ou mesmo a biomassa afogada por ocasião da formação do reservatório, pode levar a condições de produtividade primária excessiva ou à explosão de biomassa de macrófitas aquáticas flutuantes, refletindo-se, muitas vezes, na qualidade da água. Esse quadro poderá, dependendo de sua magnitude, conduzir à eliminação de grande parte da ictiofauna (AGOSTINHO et al., 1992).

A biomassa vegetal inundada demanda muito tempo para a sua decomposição e grande parte dela foi retirada durante a supressão vegetal. O processo de degradação de 
Tabela 1. Medidas de qualidade de água tomadas nos pontos do reservatório do AHE Ferreira Gomes

\begin{tabular}{|c|c|c|c|c|c|c|c|c|c|}
\hline $\begin{array}{l}\text { Profundidade } \\
\text { (m) }\end{array}$ & $\mathbf{T}\left({ }^{\circ} \mathbf{C}\right)$ & pH & $\% \mathbf{O D}$ & $\begin{array}{l}\text { OD } \\
(\mathrm{mg} / \mathrm{l})\end{array}$ & $\begin{array}{l}\text { Profundidade } \\
\text { (m) }\end{array}$ & $\mathbf{T}\left({ }^{\circ} \mathbf{C}\right)$ & pH & $\%$ OD & \begin{tabular}{|l|} 
OD \\
$(\mathrm{mg} / \mathrm{l})$
\end{tabular} \\
\hline \multicolumn{5}{|c|}{ Ponto 1 - 00 ${ }^{\circ} 50^{\prime} 57.7^{\prime \prime} 051^{\circ} 11^{\prime} 56.1^{\prime \prime} 13: 58$} & \multicolumn{5}{|c|}{ Ponto 4-0051'22" 051'11'51.6" 15:25 } \\
\hline 1 & 30.2 & 7.31 & 78.1 & 5.89 & 1 & 29.58 & 5.93 & 75.1 & 5.7 \\
\hline 2 & 29.86 & 7.19 & 75 & 5.65 & 2 & 29.45 & 6.05 & 73.1 & 5.55 \\
\hline 3 & 29.8 & 7.08 & 73.8 & 5.59 & 3 & 29.44 & 6.12 & 73.8 & 5.6 \\
\hline 4 & 29.8 & 7.05 & 73.5 & 5.58 & 4 & 29.45 & 6.15 & 73.1 & 5.57 \\
\hline 5 & 29.7 & 6.81 & 64.2 & 4.95 & 5 & 29.42 & 6.17 & 71.9 & 5.44 \\
\hline 6 & 29.58 & 6.63 & 56 & 4.27 & 5.5 & 29.41 & 6.17 & 71.3 & 5.44 \\
\hline 7 & 29.47 & 6.48 & 55.9 & 4.28 & \multicolumn{5}{|c|}{ Ponto $5-00^{\circ} 51^{\prime} 22.8^{\prime \prime} 051^{\circ} 11^{\prime} 52.8^{\prime \prime} 15: 35$} \\
\hline 7.5 & 29.46 & 6.4 & 55.8 & 4.35 & 1 & 29.91 & 6.31 & 82.2 & 6.22 \\
\hline \multicolumn{5}{|c|}{ Ponto 2 - 00 ${ }^{\circ} 51^{\prime} 07.02^{\prime \prime} 051^{\circ} 11^{\prime} 49.4^{\prime \prime} 14: 31$} & 2 & 29.91 & 6.31 & 81.8 & 6.2 \\
\hline 1 & 29.77 & 6.72 & 81.2 & 6.03 & 3 & 29.56 & 6.26 & 73.7 & 5.63 \\
\hline 2 & 29.69 & 6.57 & 77.9 & 5.93 & 4 & 29.43 & 6.19 & 73.2 & 5.58 \\
\hline 3 & 29.63 & 6.41 & 76.2 & 5.79 & 5 & 29.42 & 6.17 & 72.4 & 5.51 \\
\hline 4 & 29.49 & 6.45 & 72.4 & 5.51 & 6 & 29.4 & 6.16 & 71.7 & 5.47 \\
\hline 5 & 29.4 & 6.31 & 66.8 & 5.1 & 7 & 29.4 & 6.18 & 74.7 & 5.71 \\
\hline 6 & 29.38 & 6.24 & 65 & 4.97 & 8 & 29.41 & 6.15 & 74.4 & 5.59 \\
\hline \multicolumn{5}{|c|}{ Ponto 3 - 00 ${ }^{\circ} 51^{\prime} 12.2^{\prime \prime} 051^{\circ} 11^{\prime} 50.3^{\prime \prime} 15: 00$} & 9 & 29.41 & 6.12 & 72.8 & 5.56 \\
\hline 1 & 29.7 & 6.35 & 77.8 & 5.91 & 10 & 29.38 & 6.15 & 76.4 & 5.85 \\
\hline 2 & 29.6 & 6.35 & 75.7 & 5.74 & 11 & 29.38 & 6.17 & 77.9 & 5.95 \\
\hline 3 & 29.5 & 6.24 & 74.1 & 5.64 & 12 & 29.33 & 6.1 & 77.7 & 5.93 \\
\hline 4 & 29.4 & 6.2 & 73 & 5.57 & 13 & 29.3 & 6.16 & 78 & 5.96 \\
\hline 5 & 29.4 & 6.17 & 66.9 & 5.07 & 14 & 29.3 & 6.2 & 78.1 & 5.97 \\
\hline 6 & 29.38 & 6.17 & 64.4 & 4.93 & 15 & 29.31 & 6.11 & 77.1 & 5.94 \\
\hline 7 & 29.37 & 6.06 & 65.5 & 5.01 & 16 & 29.27 & 6.14 & 80.2 & 6.15 \\
\hline 8 & 29.36 & 6.07 & 63.8 & 4.89 & 17 & 29.28 & 6.16 & 80.2 & 6.15 \\
\hline 9 & 29.34 & 6.07 & 63.7 & 4.86 & 18 & 29.27 & 6.14 & 80.8 & 6.19 \\
\hline 10 & 29.33 & 6.01 & 68.9 & 5.27 & 19 & 29.27 & 6.27 & 80.8 & 6.18 \\
\hline 11 & 29.32 & 6.14 & 70.7 & 5.41 & \multicolumn{5}{|c|}{ Ponto 6 - 0051'29.8" 051¹151.6" 16:00 } \\
\hline 12 & 29.32 & 6.08 & 68.8 & 5.26 & 1 & 29.74 & 6.25 & 79.4 & 6.01 \\
\hline 13 & 29.31 & 6.12 & 70.2 & 5.37 & 2 & 29.69 & 6.26 & 78.6 & 5.97 \\
\hline 14 & 29.32 & 6.17 & 69.9 & 5.35 & 3 & 29.63 & 6.28 & 76.9 & 5.85 \\
\hline 15 & 29.32 & 6.22 & 69.7 & 5.33 & 4 & 29.6 & 6.21 & 76.5 & 5.82 \\
\hline 16 & 29.32 & 6.27 & 69.3 & 5.3 & 5 & 29.52 & 6.25 & 75.8 & 5.76 \\
\hline 17 & 29.32 & 6.28 & 69.7 & 5.33 & 6 & 29.44 & 6.22 & 75.4 & 5.75 \\
\hline & & & & & 7 & 29.43 & 6.14 & 75.4 & 5.74 \\
\hline
\end{tabular}

matéria orgânica causa um aumento da demanda bioquímica de oxigênio (DBO) e consequente decréscimo do OD na água.

Esse processo está acontecendo, pois parte do material vegetal não foi retirado das margens alagadas, porém não observamos decréscimo dos valores de OD a níveis intoleráveis à manutenção dos peixes, fato que causaria mortandade também na área do reservatório.

- Mortandade de peixes nas turbinas e vertedouro

A passagem de peixes do ambiente represado para jusante leva ao injuriamento do peixe ou a mortalidades cuja taxa depende da altura do vertedouro, tipo de turbina e condições de operação (CRAMER; OLIVIER, 1964). Sob 
condições de grande turbulência hidráulica ou em áreas cuja pressão se aproxima ao ponto de vaporização, a mortalidade é muito elevada. Além disso, peixes injuriados são consumidos por predadores que se concentram a jusante, o que contribui para o aumento da densidade destes (AGOSTINHO et al., 1992)

O fluxo do vertedouro já acontece há muito tempo, bem antes do início da mortandade de peixes. Portanto essa mortandade poderia estar relacionada à passagem dos peixes pelas turbinas, uma vez que o evento aconteceu concomitante ao início dos testes das mesmas. No entanto, sabe-se que a fauna de peixes a montante é diferenciada da fauna a jusante e que grande parte das espécies de peixes encontradas mortas, conhecidas como acaris (Loricariidae), são típicas de áreas com alta quantidade de pedras, como encontrado a jusante da barragem.

Logo, entende-se que os peixes mortos são residentes da área a jusante da barragem. Ainda, foi verificado que os peixes morrem continuamente todos os dias, principalmente durante o amanhecer e não exclusivamente durante os testes das turbinas.

- Alteração brusca no pH

A influência do $\mathrm{pH}$ sobre os ecossistemas aquáticos naturais dá-se diretamente devido a seus efeitos sobre a fisiologia das diversas espécies. Também o efeito indireto é muito importante podendo determinadas condições de $\mathrm{pH}$ contribuírem para a precipitação de elementos químicos tóxicos como metais pesados; outras condições podem exercer efeitos sobre as solubilidades de nutrientes (PINTO et al., 2010). Os critérios de proteção à vida aquática fixam o pH entre 6 e 9 (KUBITZA, 1998).

Segundo esse critério, todos os pontos amostrados apresentaram valores de $\mathrm{pH}$ dentro da normalidade, mostrando que não seria esse fator que estaria provocando a morte dos peixes.

- Aumento da vazão

O aumento da vazão do rio provocada pela maior abertura das comportas do vertedouro ou pela passagem de água pelas turbinas pode, em alguns casos, aumentar a correnteza do rio de forma inesperada a ponto de carregar os peixes e fazê-los chocarem-se às pedras presentes no leito. No entanto, isso também não explicaria a morte de acaris, que são peixes sedentários e que vivem escondidos em locas nas pedras. Esses peixes possuem mecanismos que fazem com que eles consigam se fixar nas pedras mesmo em locais de forte correnteza, como em grandes corredeiras, graças à sua boca ventral que funciona como ventosa e seus espinhos peitorais que os prendem entre as pedras.
- Supersaturação de oxigênio

Para Araújo et. al. (2004) o oxigênio é um importante fator no desenvolvimento de qualquer planejamento na gestão de recursos hídricos.

O oxigênio nos corpos d'água é produzido pela reaeração da atmosfera (difusão), na fotossíntese e pela entrada nos mesmos de tributários e efluentes (PINTO et al., 2010).

Segundo Agostinho et al. (1992) a incorporação de gases atmosféricos à água evertida por empreendimentos hidrelétricos pode, acima de determinados níveis, ser letal aos peixes, assim como águas com baixa concentração de oxigênio. Essas condições podem causar um efeito aos peixes chamado de embolia gasosa que pode levá-los à morte. Ainda segundo Agostinho et al. (1992) a mortalidade por embolia gasosa depende, além do nível de saturação, do tempo de exposição dos peixes a estas condições, da temperatura da água e da condição física geral do espécime (PETTS, 1984). Seus efeitos são, entretanto, limitados aos primeiros quilômetros (MACDONALD; HYATT, 1973).

Os sintomas de embolia gasosa são: formação de bolhas de gás e enfizemas no sangue e nos tecidos, bolhas de gás no intestino e na cavidade bucal, ruptura da bexiga natatória causada por uma excessiva inflagem das mesmas, hemostasia (obstrução dos vasos sanguíneos), exoftalmia (olhos saltados), entre outros (KUBITZA, 1998).

Domitrovic et al. (2000 apud KUBITZA, 2004) avaliaram o efeito da supersaturação de gases na ocorrência de doença da bolha de gás e na tolerância de juvenis de pacu expostos por diferentes tempos a concentrações de gases totais variando entre 100 a $126 \%$. Verificaram que a concentração limite que pode causar lesões relacionadas à doença da bolha de gás foi ao redor de $114 \%$ durante 24 horas contínuas de exposição.

Algumas evidências foram observadas para afirmar que a mortandade de peixes no rio Araguari a jusante do AHE Ferreira Gomes foi devido à doença da bolha de gás (embolia gasosa), causada pela supersaturação de oxigênio na água.

A primeira evidência diz respeito ao aspecto geral dos peixes mortos. Grande parte dos peixes encontrados apresentava exoftalmia (olhos protuberantes) (Figura 3). Havia peixes com bolhas na pele (figura 4) e bexiga natatória superinflada. Alguns peixes também apresentavam escoriações, provavelmente causadas por choque nas pedras quando os mesmos, após narcosados com o excesso de oxigênio chegam ao canal e não conseguem vencer a turbulência, sendo então atirados de encontro às pedras. Um dos peixes analisados apresentava bolhas de ar no seu globo ocular (Figura 5).

A segunda evidência foi observada quando a área logo a jusante da represa, na margem direita do rio Araguari, 
Figura 3. Exemplar de Leporinus fasciatus com os olhos saltados, coletado morto em frente à orla do município de Ferreira Gomes.

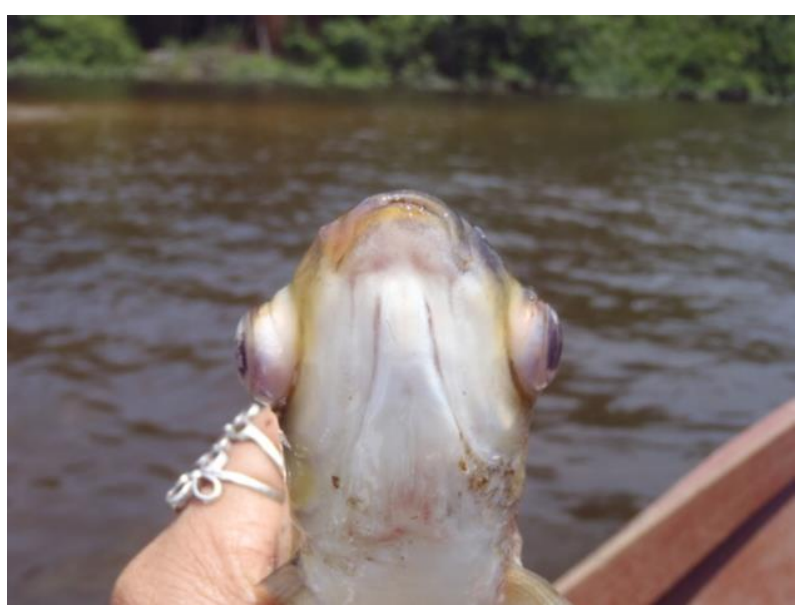

Figura 4. Exemplar de Auchenipterus cf. osteomystax com bolhas sob a pele, coletado morto próximo ao AHE Ferreira Gomes.

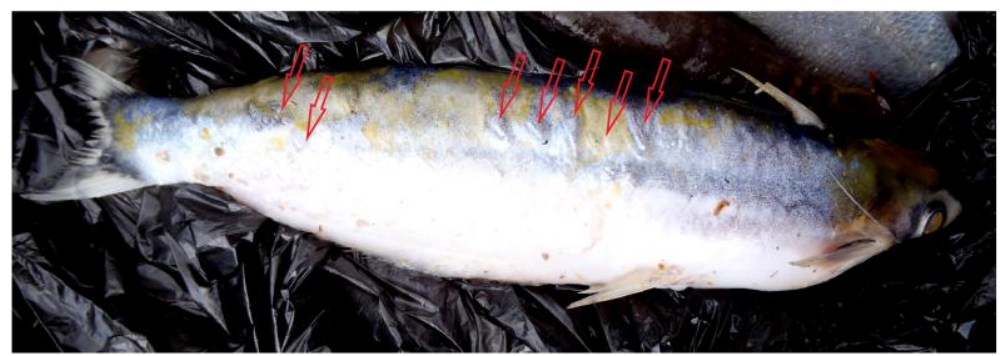

Figura 5. Exemplar de Leporinus fasciatus apresentando bolhas nos olhos coletado morto próximo ao AHE Ferreira Gomes.

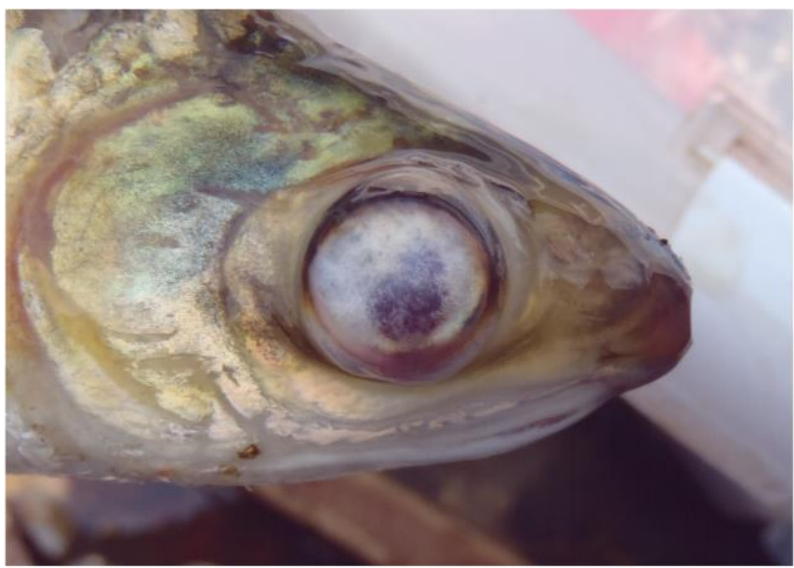

Figura 6. Imagem de formação de bolhas de gás na água localizada na margem a jusante da barragem do AHE Ferreira Gomes. Foto tirada às 7:42 AM.

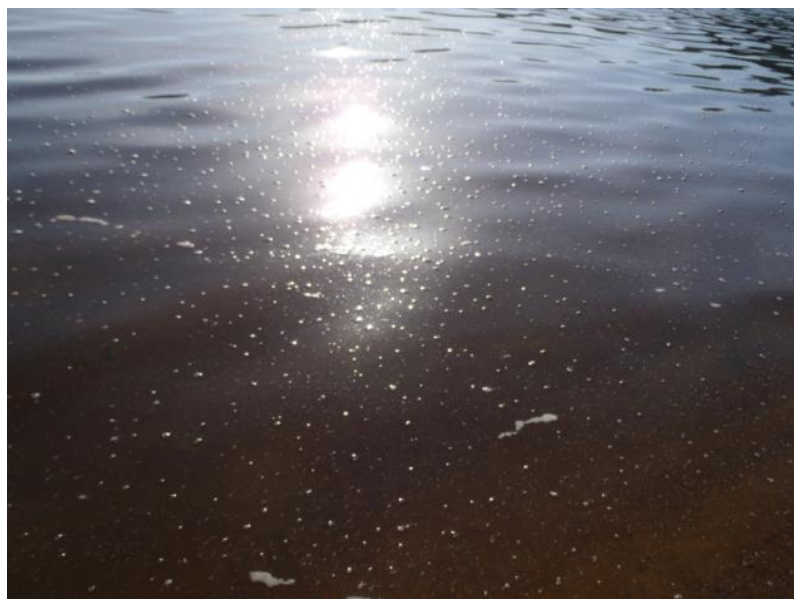


gases na água (Figura 6).

A terceira evidência diz respeito à saturação de oxigênio da água. Diferente das condições da água a montante, a água da área da margem direita do rio, logo abaixo da represa, apresentou níveis de saturação de oxigênio consideravelmente superiores. Quando foram tomadas as medidas, ao final da tarde do dia 09/10/14 (16:50 hs), a água nesta área apresentava alta temperatura, acima de $31^{\circ} \mathrm{C}$ na superfície e $29^{\circ} \mathrm{C}$ a 3 metros de profundidade (Tabela 2 ). Nessas condições, foram obtidos valores de saturação de oxigênio (\%OD) de $110 \%$ na superfície e $87 \%$ a $3,0 \mathrm{~m}$ de profundidade, além de valores de OD superiores aos do reservatório. Isso se torna ainda mais relevante ao se considerar que a capacidade da água em fixar oxigênio diminui com o aumento da temperatura. É de se esperar, portanto, que com a queda da temperatura da água durante a noite, os peixes presentes nesse local experimentem valores ainda mais altos do que os já elevados valores encontrados na vistoria, uma vez que o potencial de saturação da água aumenta nessas condições.

Vale ressaltar que no momento da amostragem a maré se encontrava em pico de vazante (baixa-mar) e a maior parte da área era inferior a $2 \mathrm{~m}$ de profundidade, possuindo saturação de $110 \%$, nas áreas mais afastadas do vertedouro (Tabela 2). É também importante destacar que a referida área, apesar da proximidade do fluxo do vertedouro, não apresenta circulação durante a maré baixa, como pode ser observado na Figura 7.

A falta de circulação da água na área por si não seria um problema relevante se não houvesse a influência de outras variáveis sobre o ambiente em questão a partir dos primeiros testes das turbinas.

A construção da barragem e a formação do reservatório provocaram uma mudança no cenário hídrico do Rio Araguari no trecho correspondente. Após o barramento do rio, o fluxo do rio passou a acontecer apenas pelo vertedouro, criando condições heterogêneas de correnteza, oxigenação e temperatura da água a jusante da barragem (Figura 7). Naquele trecho, as características da área próxima à margem direita do rio poderiam constituir um fator de risco devido à baixa profundidade, presença de pedras e consequente aumento da temperatura da água, uma vez que o fluxo direcionado do vertedouro não favorece a renovação da água presente no local em questão. Entretanto, os dois eventos diários de subida de maré amenizam tal condição, provocando uma maior dispersão da água. Pois mesmo a maré não tendo a força necessária para ocasionar uma inversão no sentido da correnteza do rio, ela reduz sensivelmente sua velocidade, agindo como uma barreira à sua vazão normal, ocasionando uma substituição da água quente e parada próximo às margens por uma água mais oxigenada vinda do vertedouro e assim uma homogeneização dos corpos d'água a jusante da barragem. Isso favorece a existência de uma fauna de peixes que necessita de águas oxigenadas como as que são encontradas em ambientes de corredeiras, classificação original do local, semelhante às condições de seca do rio (vazão reduzida) antes do surgimento da barragem.

A partir da entrada de uma nova variável nesse sistema dinâmico de movimentação de água, o cenário, então,

Tabela 2. Medidas de qualidade de água tomadas nos pontos a jusante da represa do AHE Ferreira Gomes

\begin{tabular}{|c|c|c|c|c|}
\hline Profundidade (m) & $\mathbf{T}\left({ }^{\circ} \mathbf{C}\right)$ & pH & $\% \mathrm{OD}$ & OD (mg/l) \\
\hline \multicolumn{5}{|c|}{ Ponto 1- 16:40" } \\
\hline 1 & 31.12 & 7.48 & 107.1 & 7.83 \\
\hline \multicolumn{5}{|c|}{ Ponto 2 - 16:50 } \\
\hline 1 & 31.93 & 7.34 & 110.5 & 8.08 \\
\hline \multicolumn{5}{|c|}{ Ponto 3 - 17:00 } \\
\hline 1 & 31.73 & 7.19 & 112.1 & 8.23 \\
\hline 2 & 29.48 & 6.91 & 102.9 & 7.84 \\
\hline 2.8 & 28.92 & 6.67 & 85.2 & 6.51 \\
\hline \multicolumn{5}{|c|}{ Ponto 4 - 17:15 } \\
\hline 1 & 31.26 & 6.86 & 109.8 & 8.11 \\
\hline 2 & 29.45 & 6.74 & 103.5 & 7.82 \\
\hline 3 & 28.9 & 6.5 & 87 & 6.67 \\
\hline \multicolumn{5}{|c|}{ Ponto 5 - 17:30 } \\
\hline 1 & 31.16 & 6.72 & 109.7 & 8.12 \\
\hline 2 & 31.07 & 6.76 & 109.5 & 8.13 \\
\hline
\end{tabular}


mudaria. Para a geração de energia, a água capturada a montante da represa para a ativação das turbinas sai por um fosso cavado abaixo do leito do rio à esquerda do vertedouro. Essa saída de água gera um fluxo que reduz drasticamente ou até impede a dispersão da água do vertedouro para a margem esquerda do rio, deslocando assim uma maior massa de água supersaturada para a margem direita. Tal efeito é então potencializado no período de maré enchente, devido ao seu efeito bloqueador, conforme descrito mais acima.

Figura 7. área a jusante da barragem do AHE Ferreira Gomes próxima à margem direita do rio Araguari mostrando a falta de circulação da água.

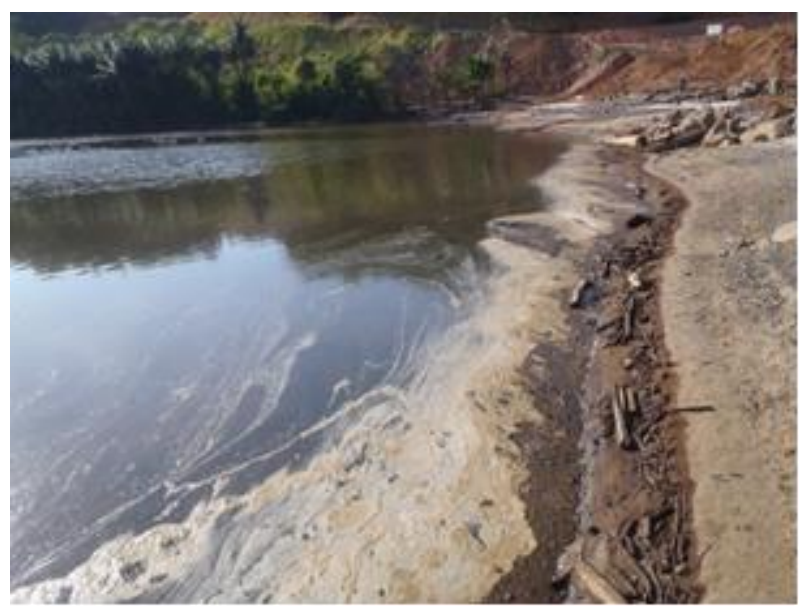

Esse cenário coincide com o depoimento da população local que associa a mortalidade de peixes ao aumento da vazão do vertedouro para fins de manutenção do nível do reservatório. Na verdade, esse aumento de vazão seria devido aos testes das turbinas que também provocam um aumento da vazão do rio, como já discutido.

\section{CONCLUSÃO}

Altas saturações de oxigênio podem levar os peixes à morte num curto espaço de tempo e quanto mais tempo os peixes ficam expostos a essa supersaturação, mais eles ficam susceptíveis aos males por ela causados. É o caso dos acaris, que não fogem do seu ambiente de vida e ficam expostos a estas condições por um tempo maior, por isso a sua mortalidade é massiva e constante. Os demais peixes, que possuem capacidade natatória mais avançada, ocasionalmente conseguem fugir do ambiente, porém com dificuldade na natação devido aos sintomas, podem ser afetados pela turbulência causada pelo vertedouro. Isso provavelmente foi a causa de terem sido encontrados peixes mortos mais a jusante com hematomas e descamação localizada.

\section{AGRADECIMENTOS}

Este estudo foi possível graças à indicação do IMAP/GEA (Instituto de Meio Ambiente e de Ordenamento Territorial do Amapá/Governo do Estado do Amapá) e ao apoio financeiro da empresa Ferreira Gomes Energia.

\section{REFERÊNCIAS BIBLIOGRAFICA}

AGOSTINHO, A. A.; FERRETTI, C. M. L.; GOMES,L. C.; HAHN, N. S.; SUZUKI, H. I.; FUGI, R.; ABUJANRA, F. Ictiofauna de dois reservatórios do rio Iguaçu em diferentes fases de colonização: Segredo e Foz do Areia.. In: AGOSTINHO, A. A.; GOMES L. C. Ed(s). Reservatório de Segredo: bases ecológicas para o manejo. Maringá: EDUEM, 1997. p. 275-292.

AGOSTINHO, A. A.; GOMES, L. C.; SUZUKI, H. I.; JULIO JR, H. F. Riscos da implantação de cultivos de espécies exóticas em tanques redes em reservatórios do Rio Iguaçu. Cadernos da Biodiversidade, v. 2, n. 2, p. 9, 1999.

AgOstinho, A. A.; PELICICE, F. M.; GOMES, L. C. Dams and the fish fauna of the Neotropical region: impacts and management related to diversity and fisheries. Brazilian Journal of Biology, n. 68 (4, suppl.), p. 1119-1132. 2008.

AGOSTINHO, A. A.; JÚLIO JR., H. F.; BORGHETTI, J. R. Considerações sobre os impactos dos represamentos na ictiofauna e medidas para sua atenuação. Um estudo de caso: Reservatório de Itaipu. Revista UNIMAR, n. 14 (suplemento), p. 89-107, 1992.

ARAÚJO, J. R. S.; NUNAN, G. W. Ictiofauna do rio Paraíba do Sul - danos ambientais e sociais causados por barragens, hidrelétricas e poluição no trecho fluminense. CPDMA ALERJ, Rio de Janeiro, 2005.

ARAÚJO, S. C. de S.; SALLES, P. S. B. de A.; SAITO, C. H. Desenvolvimento tecnológico e metodológico para medição entre usuários e comitês de bacia hidrográfica. Brasília: Departamento de Ecologia. Editora da UNB, p. 924, 2004.

BAXTER, R. M. Environmental effects of dams and impoundments. Rev. Ecol. Syst., n. 8, p. 255-283, 1977.

CARVALHO, E. D.; SILVA, V. F. B. Aspectos ecológicos da ictiofauna e da produção pesqueira do Reservatório de Jurumirim. In: HENRY, R. (ed.), Ecologia de Reservatório: Estrutura, Função e Aspectos. Botucatu: FUNDIBIO/FAPESP, 1999.

CETESB. Companhia de Tecnologia de Saneamento Básico. Significado Ambiental e Sanitário das Variáveis de 
Qualidade das Águas e dos Sedimentos e Metodologias Analíticas de Amostragem São Paulo, Séries relatórios, 41p. 2008.

CRAMER, F. K.; OLIVIER, R. C. Passing fish through hydraulic turbines. Trans. American Fisheries Society, n. 93, p. 243259, 1964.

KUBECKA, J. Succession of fish communities in reservoirs of Central and Eastern Europe. In: Straskraba, M.; Tundisi, J.G.; Duncan, A. (Ed.). Comparative reservoir limnology and water quality management, Dordrecht: Kluwer Academic, 1993.

KUBITZA, F. Coletânea de informações aplicadas ao cultivo de Tambaqui, do Pacu e de outros peixes redondos (Parte 2). Panorama da aquicultura, v. 14, n. 83, p. 13-23, 2004.

KUBITZA, F. Qualidade de água na produção de peixes - Parte III (Final) Panorama da aquicultura, v. 8, n. 47, p. 35-43, 1998.

LOWE-McCONNELL, R. H. The status on Southern America freshwater food fish. In: Zaret, T. M. (ed) Evolutionary Ecology of Neotropical freshwater fishes. Dr. W. Junk, 1984.

MACDONALD, J. R.; HYATT, R. A. Supersaturation of nitrogen in water duringpassage through HEP turbines at Mactaquac Dam. Journal off Fisheries Research Board of Canada, n. 30, p. 139-224, 1973.

PETTS, G. E. Impounded rivers: perspectives for ecological management. Chichester: John Wiley. xviii + 326 p., 1984

PINTO, A. L.; OLIVEIRA, G. H.; PEREIRA, G. A. Avaliação da eficiência da utilização do oxigênio dissolvido como principal indicador da qualidade das águas superficiais da bacia do córrego Bom Jardim, Brasilândia/MS. Geomar, v. 1, n. 1, p. 69-82, 2010.

RODRÍGUEZ RUIZ, A. Fish species composition before and after construction of a reservoir on the Guadalete River (SW Spain). Stuttgart. Archiv für Hydrobiologia, n. 142, v. 3, p. 353-369, 1998.

STRASKRABA, M.; TUNDISI, J. G. Diretrizes para o gerenciamento da qualidade da água de represas. São Carlos: IIE - Instituto Internacional de Ecologia, 2000..

Submissão: 07/10/2020

Aprovado para publicação: 14/11/2020 